This is an electronic reprint of the original article. This reprint may differ from the original in pagination and typographic detail.

Author(s): Ojala, Arto; Tyrväinen, Pasi

Title: $\quad$ Revenue models in cloud computing

Year: $\quad 2012$

Version:

Please cite the original version:

Ojala, A., \& Tyrväinen, P. (2012). Revenue models in cloud computing. In E. Prakash (Ed.), Proceedings of 5th Computer Games, Multimedia \& Allied Technology Conference (CGAT 2012) (pp. 114-119). GSTF. 5th Annual International Conference Proceedings.

All material supplied via JYX is protected by copyright and other intellectual property rights, and duplication or sale of all or part of any of the repository collections is not permitted, except that material may be duplicated by you for your research use or educational purposes in electronic or print form. You must obtain permission for any other use. Electronic or print copies may not be offered, whether for sale or otherwise to anyone who is not an authorised user. 


\title{
Revenue Models in Cloud Computing
}

\author{
Arto Ojala and Pasi Tyrväinen \\ Department of Computer Science and Information Systems \\ University of Jyväskylä \\ Jyväskylä, Finland \\ arto.k.ojala@jyu.fi; pasi.tyrvainen@jyu.fi
}

\begin{abstract}
Cloud computing brings new possibilities, allowing software firms to sell their software products using the Software-as-a-Service (SaaS) model. SaaS provides opportunities for flexible pricing but creates challenges on how to achieve a profitable revenue stream. In this multicase study, the revenue models of five SaaS providers were examined. The main interest of the study was to investigate the different revenue models and the reasons for using particular revenue models. The revenue models were found to be mainly based on software renting, with a variety of pricing strategies. For SaaS providers, software renting generates a steady and predictable stream of revenue. The software renting model is also attractive to customers because (i) it facilitates prediction of the actual costs of the software, (ii) it decreases initial investments costs, and (iii) it makes it possible to purchase the software without special budgeting or the approval of top management. Interestingly, none of the firms used the commonly cited pay-per-use model.
\end{abstract}

Keywords- Cloud computing; Revenue models; Cloud business models; Case study

\section{INTRODUCTION}

Cloud computing is changing the way in which software is delivered, sold and used. In cloud computing, software is delivered to customers via the Internet as a service. For the customers, SaaS provides online access to software when needed instead of having it permanently installed on their own computers. This reduces costs, since pricing is more flexible than in the case of traditional software licensing. SaaS also ensures that the latest version of the software is in use without continuous installation of updates. In addition, because the software is executed on a service provider's server, it frees users from worrying about the technical specification of the computer or the data storage capacity. However, for a software vendor, this model brings new challenges connected with ensuring a profitable revenue stream when an initial license fee is replaced by a rent or usagebased fee [13].
Despite the extensive literature on pricing and license strategies for software and other information goods $[2,3,6,12]$ we do not know much about the revenue models used in cloud computing, or about the reasons why firms use a particular revenue model. This is important, since the SaaS model has many possibilities for flexible and attractive pricing for customers. On the other hand, the lower switching cost of the SaaS offering makes it more of a challenge to keep existing customers [7], and consequently, to cover the high development costs.

This paper focuses on SaaS providers and their revenue models, while recognizing that cloud computing includes also Infrastructure-asa-Service (IaaS) providers and Platform-as-aService (PaaS) providers. The reason for this choice is based on the rapidly growing number of SaaS service providers and users in the market [15, 18]. A study by Armbrust et al. [1] also highlights the fact that SaaS providers have received less attention than SaaS users.

Based on the considerations, this article will describe various revenue models used by SaaS providers, and more specifically, the reasons for the use of a particular revenue model or combination of models. The following question is of addressed: Why do software firms in the SaaS business use particular revenue models? The study thus seeks to contribute to the knowledge available on cloud computing related revenue models.

\section{LITERATURE REVIEW}

\section{A. Cloud Computing}

Cloud computing refers to the provision of computing capacity, storage capacity, and applications as a service across the Internet. In line with Armbrust et al. [1], cloud computing is considered here to cover software applications delivered through the Internet, and the hardware and system software that is used within data centers to provide these services. The data center hardware and software that form a "cloud" [1] can be divided into a public cloud, a private 
cloud, and a hybrid cloud. In a public cloud, a software vendor uses its own or a third party's cloud infrastructure (data center) to offer SaaS for customers in a pay-as-you-go manner. A private cloud involves the customer's internal data center, where the software is installed and used in a centralized manner within the organization, that is, the software is not made publicly available [1, 10]. In the case of a hybrid cloud, a firm using a private cloud may, for example, offload part of the workload to a public cloud and in that way acquire more computing capacity $[10,16,20]$.

A common reason to use a private cloud instead of a public cloud is related to concerns about data security $[1,8]$. If a firm's data is stored on a public cloud, it may not know precisely where the data is stored, and there may well be other data sources that are collectively stored along with the firm's data [8,9]. Since cloud computing is a very new phenomenon, concerns may be also related to national governments possibly having access to the information if the data flows over national borders [8]. Armbrust et al. [1] list ten obstacles in cloud computing that might limit customers' willingness to use a public cloud infrastructure. These obstacles are related to worries about business continuity and service availability, data lock-in, data confidentiality and auditability, data transfer bottlenecks, performance unpredictability, scalability of the storage, bugs in the distribution system, scaling time, reputation fate-sharing, and limitations in licensing. However, although data security seems to be the major concern, Creeger [4] points out that $75-80$ percent of intellectual property breaches take place inside the firm; hence this issue should not rationally impact on a decision to use public cloud services.

\section{B. Revenue Models in Software Business}

In line with Sainio and Marjakoski [14], a revenue model is here seen as an operational description, indicating how a firm collects revenue from its customers. In other words, it relates to the various options that a firm may offer to customers who might wish to buy its software.

In traditional software revenue models, software is sold as a packaged or perpetual license. In packaged licensing, a customer buys a single license for single user or computer, whereas in perpetual licensing, the software is bought for a certain number of users or computers. Hence, the number of computers on which the software can run is limited. In addition to the initial license fee, customers commonly have to pay a maintenance fee, which includes technical support and version updates [6]. In this study, the term "traditional license" is used to describe these two options.

SaaS involves a new way of delivering and selling software. In an SaaS model, the software is licensed for a fixed term by applying a usage or periodic subscription fee $[3,7,21]$. In the literature, cloud or SaaS providers have been commonly referred to as adhering to a pay-peruse method $[1,10,12]$. This refers to charging the customer on the basis of metered usage of serverhours. This differs from software renting, in which the customer pays a negotiated subscription fee for a certain time period [1]. Altogether, the use of SaaS lowers customers' initial investment costs, since they pay only for services when they are needed (pay-per-use) or periodically (e.g. pay-per-month).

From the considerations above, it would seem that there are some similarities between traditional revenue models and the revenue models available through SaaS. However, the main difference is that in the SaaS model, the software is available through a public or private cloud and is delivered to the users' devices through the Internet or Intranet.

\section{METHODOLOGY}

The present study applies a multiple case study methodology similar to the approaches introduced by Eisenhardt [5] and Yin [19]. This method enables an in-depth investigation and explanation of the phenomenon. It also makes it possible to use replication logic, so that the researchers are able to identify the subtle similarities and differences within a collection of cases $[5,19]$.

The research setting for this study consisted of five software firms operating in the cloud computing business (see Table 1) as SaaS providers. Three of the firms were dealing with a national cloud software program in Finland, and two firms were contacted on the basis of the industry knowledge of the author. Thus, the most important selection criterion was good access to the required information, as recommended by Stake [17]. The personal-contact aspect increased mutual trust between the researcher and the persons interviewed in the case firms, and consequently, facilitated the collection of accurate information.

Multiple sources of information were used to gather data from each case firm. The main form of data collection was a semi-structured interview, guided by a list of topics. Altogether, there were 21 semi-structured open-ended interviews with two to five informants from each 
TABLE I. OVERVIEW OF THE CASE FIRMS

\begin{tabular}{|c|c|c|c|c|}
\hline Firm & $\begin{array}{c}\text { Year of } \\
\text { establishment }\end{array}$ & Product/ service & Delivery channel & Revenue model(s) \\
\hline Firm A & 1998 & $\begin{array}{l}\text { - Planning and optimization } \\
\text { software for telecom } \\
\text { operators }\end{array}$ & $\begin{array}{l}\text { - Public and private } \\
\text { cloud }\end{array}$ & $\begin{array}{c}\text { - Renting } \\
\text { - Traditional licensing }\end{array}$ \\
\hline Firm B & 2000 & $\begin{array}{l}\text { - Gaming platform } \\
\text { - Game content for the } \\
\text { platform }\end{array}$ & - Public cloud & - Renting \\
\hline Firm C & 2006 & $\begin{array}{l}\text { - Risk management software } \\
\text { for banks }\end{array}$ & - Private cloud & $\begin{array}{c}\text { - Renting } \\
\text { - Traditional licensing }\end{array}$ \\
\hline Firm D & 2008 & $\begin{array}{l}\text { - Entitlement management } \\
\text { software }\end{array}$ & $\begin{array}{l}\text { - Public and private } \\
\text { cloud }\end{array}$ & $\begin{array}{c}\text { - Renting } \\
\text { - Traditional licensing }\end{array}$ \\
\hline Firm E & 2006 & $\begin{array}{c}\text { - Interactive 3D sales } \\
\text { software }\end{array}$ & $\begin{array}{l}\text { - Public and private } \\
\text { cloud }\end{array}$ & - Renting \\
\hline
\end{tabular}

case firm. Having two or more interviews from each case firm made it possible to ask more detailed questions of the second interviewee, following on from the first interview. Working in this way improved the validity of the data collected. All the interviews (lasting 45-90 minutes) were digitally recorded and transcribed verbatim by the author. A second listening was carried out to ensure correspondence between the recorded and the transcribed data. The complete case reports were then sent back to the interviewees for comment, and any inaccuracies they noticed were corrected. In addition, e-mail and telephone communication was used to collect further information and to clarify inconsistent issues if necessary. A further step at this point was to look at many types of secondary information sources (websites, annual reports, press releases, etc.). By comparing the interview data with other documents from the case firms, the information collected was triangulated [11]. This increased the validity of the interview data, and made it possible to formulate further questions to clarify incoherent information [19].

\section{FINDINGS}

This section will present the case firms' revenue models and the reasons for the use of a particular model. Table 1 summarizes key information on the case firms.

Firm $A$ offers planning and optimization services/software for telecom operators. In its business, Firm A uses software renting and traditional licensing. In the rental model, the amount of revenue is based on the number of users and the length of the agreement. Agreements are commonly made for at least three months. A longer agreement reduces the monthly fee for the software. However, pricing is fairly flexible and is negotiated with each customer separately. Nevertheless, not all customers wish to use the software through a public cloud, because of security concerns. The vice president of the firm commented on this as follows: "This industry is quite conservative. Saas brings new opportunities but it doesn't mean that the customer is ready to accept it. Thus, we have to have the possibility to offer the product using an old revenue model." For these customers, Firm A has a traditional licensing model available, in which a customer buys a traditional license for a workstation or uses the software in its private cloud. Another reason to sell a traditional license for a workstation is the unavailability of network connections in some cases where a customer is in the process of building a new telecom network. A pay-per-use method was not considered by this firm, since software renting was seen as a safer pricing method (due to the fact that the amount of the actual usage was difficult to estimate). In addition, they saw that pay-per-use method makes their business more complex as it requires a technical solution to measure transactions and maintenance of auditable records of usage.

Firm $B$ provides interactive gaming platforms and games-on-demand services. The firm licenses game content from game developers and converts these games to its gaming platform. The network operators operate the platform and deliver games to players' set-top boxes or PCs through their broadband network subscribers. The revenue model is based on software renting with a variety of payment options for consumers. These options include a subscription for a particular game for 24 hours, a monthly subscription for all the games available in the service, and a subscription for different games packages for a certain time period. This model provides flexible payment 
options for consumers, and these increase the attractiveness of the service compared to the traditional way of buying games from a store. The CEO of the firm expressed this as follows: "This revenue model allows very interesting pricing strategies. Instead of buying the game from a store, this makes it possible to rent the game for a day...or the game can be a part of a games package that can be used, for example, for a month." Other revenue models were not suitable, as the games are offered as a service in the Firm B business model. For the network operators who delivered the games, a rent-based fee was simpler to use and charge than a pay-peruse model.

Firm $C$ offers risk management software for banks. Since the software is used to handle highly confidential data related to bank transactions, the service is provided in a private cloud. However, the firm also has a demo version of the software that is available through a public cloud. The CEO of the firm explained this as follows: "The software is related to the banks' core know-how, they do not let the information go outside the bank...this is related to their own cash flow, it is the biggest secret that they have”. Firm $\mathrm{C}$ uses two revenue models. The first model is traditional licensing including a license fee and an annual maintenance fee. The second option is to rent the software. The initial rental agreement is made for a two-year period and then renewed for a year at a time, or else according to an agreement with the customer. The rental fee is commonly paid monthly. Renting is seen as a good option, especially for smaller customers that do not have a budget for the kind of initial investments that traditional software licensing requires. The CEO commented on this as follows: "Previously we only had a traditional licensing model - an initial license fee plus an annual maintenance fee. However, we are now moving increasingly towards a license-renting model in which we charge a monthly rental fee. Then the bank doesn't have to make an investment decision, it just pays the monthly rental fee. Then it is more like a cost, not an investment." The traditional license or rental fee depends on the number of users, the functionalities of the software, and the size of the customer. The use of two different revenue models is seen as a good way to offer alternatives to customers.

Firm $D$ develops software for entitlement management. The software is available to customers through a rental model, or else a customer can select a traditional software license.
In the rental model, an operator who hosts the cloud service is charged according to a monthly fee that is dependent on the estimated number of users. In some cases, customers want to buy a license in the traditional way and use the software in their private cloud. The traditional license fee includes an initial license fee based on the number of features included, and an annual maintenance fee. The sales manager of the firm explained the software offering in the following manner: "We like to have both options available (rental and traditional license) for customers, because both are sought by the customers. We do not want to turn this into a restrictive issue." The traditional license was mainly for customers who had concerns about the security or reliability of the public cloud.

Firm E sells interactive 3D sales software for furniture manufacturers and furniture retailers. Firm E also models the customers' furniture elements for their 3D software, and encodes the rules for how different furniture elements can be attached to each other. The revenue model is based on an implementation fee and an annual rent fee. The implementation fee includes software implementation for the customer, activation, and visualization. The initial rental agreement is for three years and thereafter a customer can renew it for a fixed period. The amount of the rent fee depends on the functionalities and the number of furniture elements included in the software. The customer may start using the software with the inclusion of only a basic function, then purchase more functionality as required. New furniture elements can also included in the software later on. The $\mathrm{CEO}$ of the firm explained this as follows: "We apply a yearly rent fee and then content production and activation fees. When the system is activated, we can bring in new content all the time. The customer may start with one collection of furniture, but they may have ten collections or have the collections recur." As the software required a lot of implementation work, having a three-year subscription agreement ensures that Firm E can cover the development of the software. The rental model was seen as simpler to use than the pay-per-use method, which would require metering of the actual software usage. Most of the customers used the software through a public cloud, but in some cases in which a large customer had its own servers available, the software was used within a private cloud. 
TABLE II. DELIVERY AND REVENUE MODELS OF THE CASE FIRMS

\begin{tabular}{|l|l|l|l|}
\hline & \multicolumn{1}{|c|}{ Traditional licensing } & \multicolumn{1}{|c|}{ Software renting } & \multicolumn{1}{c|}{ Pay-per-use } \\
\hline Workstation & A & - & - \\
\hline Private cloud & A, C, D & A, C, E & - \\
\hline Public cloud & - & A, B, D, E & - \\
\hline
\end{tabular}

\section{DISCUSSION}

The findings indicated that the SaaS providers used software renting and traditional licensing as their primary revenue models. The major observations are summarized in Table 2. Interestingly, none of the firms interviewed used pay-per-use pricing, despite the fact that in the literature it is the most commonly cited revenue model for cloud computing $[1,10,12]$. The case firms saw pay-per-use pricing as a more complex than software renting. In addition, they thought that pay-per-use requires technical tools to measure the actual usage of the software. Furthermore, it requires maintenance of auditable records of the each customer usage. This decreased the case firms interest to use the payper-use model.

The first major observation relates to financial predictability. For the providers, software renting was a less risky way to cover development costs than pay-per-use pricing; it generated a steady stream of revenue, and made it possible to predict the revenue from customers. For the customers, software renting made it possible to predict the actual costs of the software. It was also attractive to them because they were not obliged to make high initial investments to obtain a software license, as would have been the case with traditional licensing. For the customers, this also provided added value in terms of flexibility. Shifting capital investment onto the operational cost enabled them to start using the software without special budgeting or the approval of top management.

Within their software rental model, the case firms used various pricing strategies. In these strategies, the rent fee was priced according to the number of users, the length of the agreement, the size of the customer (the client firm), and/or the functionalities included in the software. This means that traditional license conditions, such as "pay per seat," were transformed into "pay per feature or functionality," even though the software was delivered through the Internet. The length of the subscription varied from 24 hours to three years. However, most of the case firms indicated that the length of the agreement was negotiated separately with each customer.

A traditional software license was available in three cases (firms A, C, and D). The firms saw this as a flexible way to serve customers, offering them also the possibility to buy a traditional software license. In these cases, the customers bought the license and then paid an annual maintenance fee. Compared to software renting, this model included high initial investments, but the annual maintenance fee was much lower than the rental fee, and the result was a lower total cost for long contract periods.

One notable reason for providing flexible software offering and revenue models was the customers' concerns regarding software offerings through a public cloud. Some of the customers did not trust SaaS offerings through a public cloud, preferring to use the software either in a private cloud or to buy a traditional license for a workstation. The customers thought that by using a public cloud they would lose control over their own data. This finding is in line with points made by Kaufman [8] and Armbrust et al. [1], relating to SaaS users' concerns that they will lose control of their data if it is stored in a public cloud. Indeed, a lack of trust in public clouds is one of the most important challenges in cloud computing [9]. As regards revenue models, the findings here show that it is good to have alternative options available for customers who are concerned about data security in the public cloud. Otherwise, the firm may simply lose these customers.

\section{CONCLUSIONS}

Altogether, the findings here indicate that SaaS providers favor software renting as the primary revenue model. Software renting provided a predictable and less risky revenue stream. In addition, it was easier and simpler to use compared to pay-per-use method. From the customers' point of view, software renting made it possible to estimate the costs of software and to buy the software without special budgeting or long decision processes. Many features of traditional licensing were transformed into 
pricing model features in SaaS. For customers who had concerns about data security in a public cloud, the SaaS vendors could make a traditional software license available, and could make it possible to rent the software over a private cloud.

In contributing to an understanding of the revenue model in cloud computing, this study also points to aspects requiring further study. The aim here was to achieve a broad understanding of the phenomenon; hence, further studies could seek to measure how profitable different revenue models are, and in what circumstances is it beneficial to use a particular revenue model. The aim here was not to generalize the findings. Instead, we liked to find the reasons behind usage of different revenue models. Thus, further (quantitative) studies could seek to measure how common certain revenue models are.

\section{ACKNOWLEDGMENT}

The research reported in this paper was carried out within the framework of the Cloud Software Program which was governed by TIVIT Oy nominated to organize and manage the programs of the Strategic Center for Science, Technology and Innovation in the field of ICT funded by the Finnish Funding Agency for Technology and Innovation (TEKES). In addition, the authors would like to thank financial support from Finnish Foundation for Economic Education for this study.

\section{REFERENCES}

[1] Armbrust et al. (2010) "A view of cloud computing," Communication of the ACM, 53, 4, 50-58.

[2] Bakos, Y. and Brynjolfsson, E. (1999) "Bundling Information Goods: Pricing, Profits, and Efficiency," Management Science, 45, 12, 16131630.

[3] Choudhary, V. (2007) "Comparison of Software Quality Under Perpetual Licensing and Software as a Service," Journal of Management Information Systems, 24, 2, 141-165.

[4] Creeger, M. (2009) "Cloud computing: An overview," ACM Quaue, 7, 5, 1-5.

[5] Eisenhardt, K.M. (1989) "Building theories from case study research," Academy of Management Review, 14, 4, 532-550.

[6] Ferrante, D. (2006) "Software Licensing Models: What's Out There?," IT Professional, 8, 6, 2429.

[7] Huang, K-W. and Wang, M. (2009) "Firm-Level Productivity Analysis for Software as a Service Companies," Proceedings of the ICIS 2009.

[8] Kaufman, L.M. (2009) "Data Security in the World of Cloud Computing," IEEE Security and Privacy, 7, 4, 61-64.
[9] Khan, K.M. and Malluhi, Q. (2010) "Establishing Trust in Cloud Computing," IT Professional, 12, 5, 20-27.

[10] Louridas, P. (2010) "Up in the Air: Moving Your Applications to the Cloud," IEEE Software, 27, 4, 6-11.

[11] Miles, M.B. and Huberman A.M. (1994) Qualitative Data Analysis: An Expanded Sourcebook. California: Sage Publications.

[12] Mäkilä, T., Järvi, A., Rönkkö, M. and Nissilä, J. (2010) "How to Define Software-as-a-Service An Empirical Study of Finnish SaaS Providers," In Tyrväinen, P., Jansen, S. and Cusumano, M.A (Eds.) Software Business, Springer, Berlin, 115124.

[13] Ojala, A. and Tyrväinen, P. (2011) "Developing Cloud Business Models: A Case Study on Cloud Gaming," IEEE Software, vol. 28 , no. 4, pp. 42-47.

[14] Sainio, L-M. and Marjakoski, E. (2009) "The logic of revenue logic? Strategic and operational levels of pricing in the context of software business," Technovation, 29, 5, 368-378.

[15] SIIA (2011), "All about the cloud," Software \& Information Industry Association, available at: www.siia.net/aatc/2011 (accessed 6 April 2011).

[16] Sotomayor, B., Montero, R.S., Llorente, I.M. and Foster, I. (2009) "Virtual Infrastructure Management in Private and Hybrid Clouds," IEEE Internet Computing, 13, 5, 14-22.

[17] Stake, R.E. (1995) The art of case study research, Sage Publications.

[18] TenWolde, E.K. (2007) "SaaS 2.0: What Does the Future Hold," OpSource SaaS Summit, IDC

[19] Yin, R.K. (2009), "Case study research: Design and methods," CA: SAGE Publications.

[20] Mazhelis, O. and Tyrväinen, P. (2011) "Economic Aspects of Hybrid Cloud Infrastructure: User Organization Perspective," Information Systems Frontiers, Online First, 13 September 2011.

[21] Tyrväinen, P. and Selin, J. (2011) "How to Sell SaaS: A Model for Main Factors of Marketing and Selling Software-as-a-Service," in Proc. of ICSOB2011, the $2^{\text {nd }}$ International Conference on Software Business, Brussels, June 8-10, 2011. pp. 